\title{
Development of Microstrip Patch Antenna Design for S-Band Application
}

\author{
Naw Khu Say Wah, Hla MyoTun \\ Department of Electronic Engineering, Yangon Technological University, Yangon, Republic of the Union of Myanmar
}

\section{Email address:}

nawkhusaywah.ytu@gmail.com (N. K. S. Wah), hmyotun@gmail.com (H. M. Tun)

\section{To cite this article:}

Naw Khu Say Wah, Hla MyoTun. Development of Microstrip Patch Antenna Designfor S-Band Application. American Journal of Electromagnetics and Applications. Vol. 6, No. 1, 2018, pp. 17-23. doi: 10.11648/j.ajea.20180601.13

Received: February 17, 2018; Accepted: March 7, 2018; Published: March 29, 2018

\begin{abstract}
Microstrip patch antenna used to send onboard parameters of article to the ground while under operating conditions. The aim of the paper is to design as tacked nearly square microstrip patch antenna design for $\mathrm{S}$ band $2 \mathrm{GHz}$ to 4 $\mathrm{GHz}$ and study the effect of antenna dimensions Length (L), and substrate parameters relative Dielectric constant ( $\varepsilon r$ ), substrate thickness (h) on the radiation parameters of Bandwidth and Beam-width. A stacked patch configuration is proposed to increase the narrow bandwidth, radiation efficiency and directivity. The proposed antenna is probe fed on a FR-4 substrate with dielectric constant of 4.4. At resonant frequency $2.42 \mathrm{GHz}$, antenna parameters like Return Loss, VSWR, Axial Ratio and Radiation pattern are verify and simulated on CST Microwave Studio by CST student edition.
\end{abstract}

Keywords: Electromagnetic Theory, CST Microwave Studio, Microstrip PatchAntenna, Stacked Patches, S-Band, Polarization

\section{Introduction}

ThisMicrostrip antenna has been one of the mostinnovative topics in antenna theory and design in recent years, and is increasingly finding application in a wide range of modern microwave systems [6]. Deschamps first proposed the concept of the MSA in 1953 [2]. However, practical antennas were developed by Munson [3]-[4] and Howell [5] in the 1970s. Microstrip antennas (MSA) offer many attractive features such as low weight, small size, ease of fabrication, ease of integration with Microwave Integrated Circuits (MIC) and can be made conformal to host surface. However, they suffer from low gain, narrow bandwidth, low efficiency, and low power handling capability [7]-[9]. In some applications, such as in government security systems, narrow bandwidths are desirable [7]. This proposed antenna has square patch used. The square patch is by far the most widely used configuration. It is very easy to analyze using both the transmission-line and cavity models, which are most accurate for thin substrates [7].

\section{Antenna Design}

The antenna design could be developed based on the following steps and analyses.

\subsection{Mathematical Analysis}

The design of the proposed antenna is shown in Figure 1. The design of the proposed microstrip patch antenna was modeled the classical equations.

Step 1: Calculation of the Width (W):

$$
\mathrm{W}=\frac{\lambda}{2}\left[\sqrt{\frac{\varepsilon r+1}{2}}\right], c=\frac{f r}{\lambda}
$$

Where $\mathrm{c}=3 \times 10^{8} \mathrm{~m} / \mathrm{s}, \mathcal{E} \mathrm{r}=4.4, \mathrm{fr}=$ Designed Frequency Step: Calculation of Effective dielectric constant (Ere):

$$
\varepsilon r e=\frac{\varepsilon r+1}{2}+\frac{\varepsilon r-1}{2}\left[1+\frac{10 h}{W}\right]^{-0.5}
$$

Where $\mathrm{h}=1.6 \mathrm{~mm}$

Step 3: Calculation of the Effective length ( $\left.\mathrm{L}_{\mathrm{eff}}\right)$

$$
L_{e f f}=0.5 \frac{\lambda}{\sqrt{\varepsilon r}}
$$

Step 4: Calculation of the length extension $(\Delta \mathrm{L})$ : 


$$
\Delta L=0.412\left(\frac{\varepsilon r e+0.3}{\text { cre }-0.3}\right) \frac{\left[\frac{W}{t}+0.264\right]}{\left[\frac{W}{t}+0.8\right]} h
$$

Step 5: Calculation of actual length of patch (L):

$$
\mathrm{L}=\mathrm{L}_{\mathrm{eff}}-2 \Delta \mathrm{L}
$$

Step 6: Calculation of input impedance:

$$
Z_{A}(\Delta x p=0)=90 \frac{\varepsilon r^{2}}{\varepsilon r-1}\left[\frac{L}{W}\right]^{2} \Omega
$$

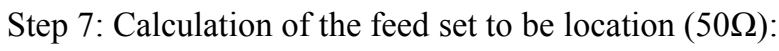

$$
\Delta x p=\frac{L}{\pi} \cos ^{-1} \sqrt{\frac{Z_{A}(\Delta x p)}{Z_{A}(\Delta x p=0)}}
$$

Step 8: Calculation of ground plane size

$$
\begin{gathered}
\mathrm{L}_{\mathrm{g}}=6 \mathrm{~h}+\mathrm{L}_{\text {patch }} \\
\mathrm{W}_{\mathrm{g}}=6 \mathrm{~h}+\mathrm{W}_{\text {Patch }}
\end{gathered}
$$

\subsection{Proposed Antenna Geometry}

For microstrip antennas, a good first step to assume a standard substrate, to know importance of $\mathcal{E}$ r, h, to avoid cross polarization the antenna must be kept $1<\mathrm{W} / \mathrm{L}<1.5$ and rule of $\lambda / 2$ versus $\sim 0.48 \lambda$.

Figure 1 shows a 3D model of a proposed $\mathrm{s}$ band patch antenna. The upper patch resembles a truncated corner nearly square patch with a total size of $28.55 \times 27.33 \mathrm{~mm}^{2}$. There are many ways to get circular polarization for the patch antennas. Common ways to achieve circular polarization is by cutting corner of the patch. In the proposed design, the antenna is truncated to get left handed circular polarization or LHCP. The lower patch has a same size with the upper patch shape with different slots as v-slit, 1- slit. The purpose with these different structures for the patch layer is that the current needs to travel a longer way on the patch surface which increases the electrical length. One of the methods to increase the bandwidth is using a thick substrate layer such as stack more than one radiation path. The size of the ground plane can also be used to increase the bandwidth. Feeding techniques is mainly to transfer the power to the patch. There are many ways to feed the patch and all have their disadvantages and advantages. The coaxial feed method is one of the common feed techniques. It is easy to match because the feed position can be placed anywhere to the patch to get impedance matching but narrow bandwidth.

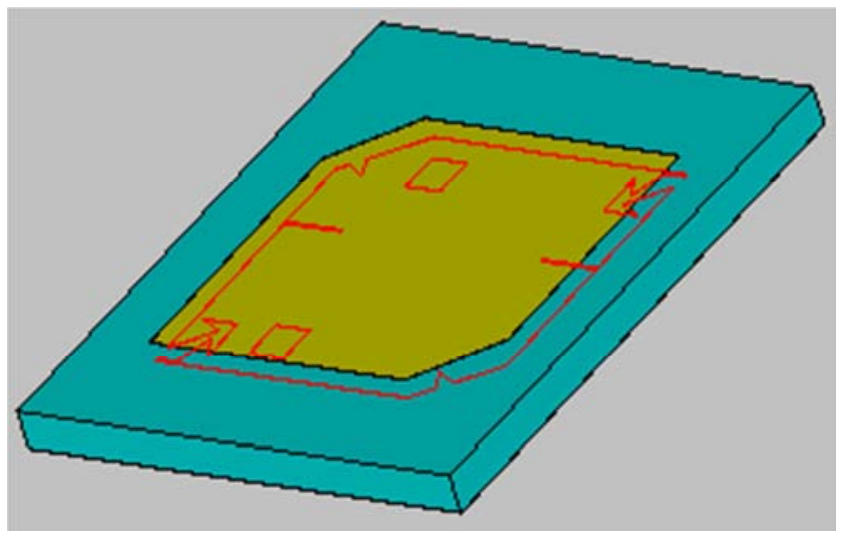

\begin{tabular}{|c|c|c|c|c|c|}
\hline \multicolumn{6}{|c|}{ Antennas Theory and Design PP.469-471 } \\
\hline Width & 2.7 & 0.608581 & 38.03629 & & \\
\hline Effective dielectric constant & 2.7 & 1.7 & 1.420651 & 0.838989 & 4.126281 \\
\hline Length & 28.32003 & & & & \\
\hline $\mathrm{ZA}$ & 284.0928 & & & & \\
\hline Delta_x & 0.419522 & 1.137877 & 10.26265 & & \\
\hline Ground Width & & & & 54.72003 & \\
\hline Ground Length & & & & 64.43629 & \\
\hline
\end{tabular}

Figure 1. Front view of the Microstrip Patch Antenna.

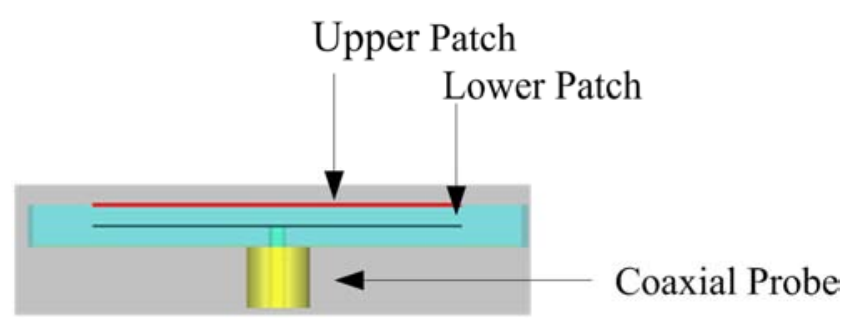

Figure 2. Side view of the Microstrip Patch Antenna.

Table 1. Calculation Of Antenna Parameters In Excel.

\begin{tabular}{lll}
\hline Input_data 1 & frequency & 2.4 \\
& one-wavelength & 125 \\
Input_data 2 & dielectric constant & 4.4 \\
Input_data 3 & thickness & 1.6 \\
\hline
\end{tabular}


Table 2. Design Parpmeter Specifications Of The Rectangular Microstrip Patch Antenna.

\begin{tabular}{ll}
\hline Dielectric Constant of the substrate & FR-4 (Lossy) \\
\hline Height of the dieletric substrate (h1\&h2) & $1.6 \mathrm{~mm}$ \\
Height (t) of Patch and Ground & $0.035 \mathrm{~mm}$ \\
Patch Length (upper\& lower) & $27.33 \mathrm{~mm}$ \\
Patch Width (upper \&lower) & $28.55 \mathrm{~mm}$ \\
Substrate and Ground Length & $37.83 \mathrm{~mm}$ \\
Substrate and Ground Width & $47.56 \mathrm{~mm}$ \\
Design frequency & $2.4 \mathrm{GHz}$ \\
Feed location (x, y) & $(0,10.7) \mathrm{mm}$ \\
Feed Diameter & $1.3 \mathrm{~mm}$ \\
Feeding technique & Coaxial Probe \\
\hline
\end{tabular}

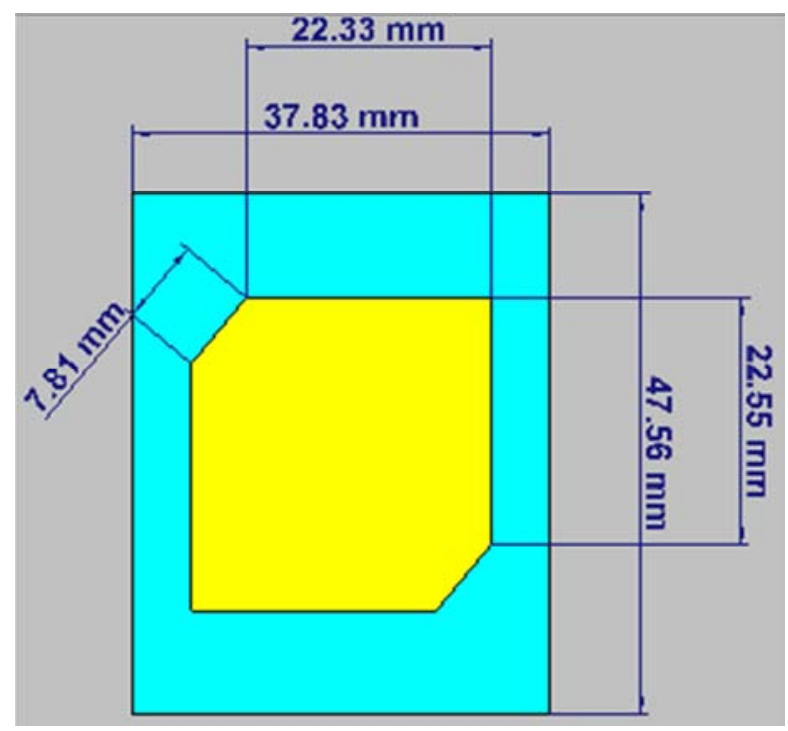

(a) Upper Patch

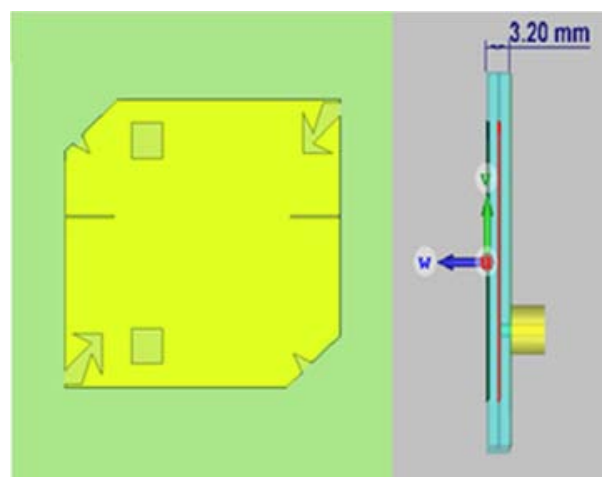

(b) Lower Patch (c) Stacked Height

Figure 3. Stacked TruncatedPatch Antenna Designed using CST Microwave Studio.

\section{Results and Discussions}

The simulated return loss $(\mathrm{S} 1,1)$ of the proposed antenna is depicted in Figure 4 and Figure 5. The graph shows the maximumreturn loss of $-16.207 \mathrm{~dB}$ at the resonant frequency 2.42GHz. The graph also depicts that below $-10 \mathrm{~dB}$ theantenna attained the bandwidth of $0.16024 \mathrm{GHz}(6.67 \%)$ The voltage standing wave ratio (VSWR) of the proposedantenna is shown in. Figure 6. It can be observed from the resultthat the VSWR value is less than 2 for whole operating band, which considered as suitable for the antenna. Figure 7 and Figure 8 depict far field radiation directivity and far- field radiation gain of proposed antenna respectively. Directivity and Gain is 5.78 $\mathrm{dBi}$ and $5.44 \mathrm{~dB}$ respectively. Figure 9 and Figure 10 shows 3D radiation pattern. Beamwidth is 91.7 at $3 \mathrm{~dB}$. Table 3 shows the summary of results of the proposed patch antenna.

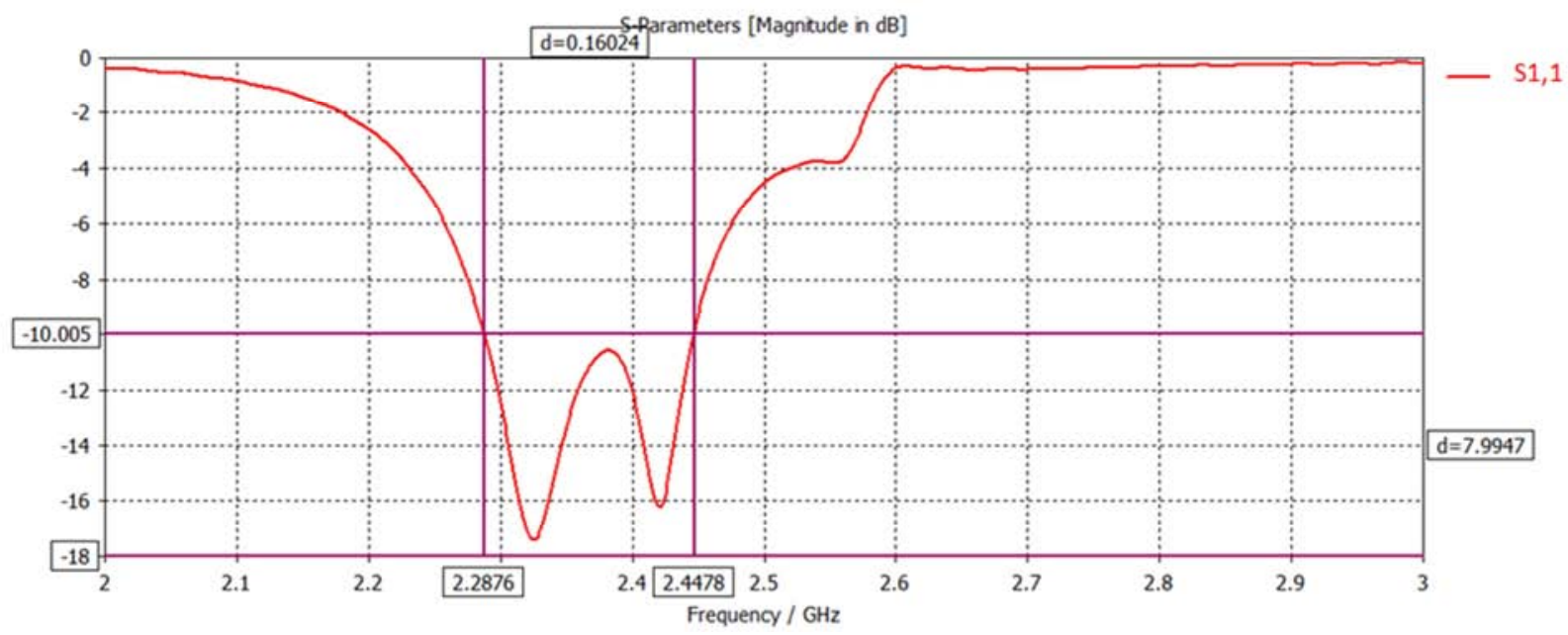

Figure 4. Return Loss vs. Frequency. 


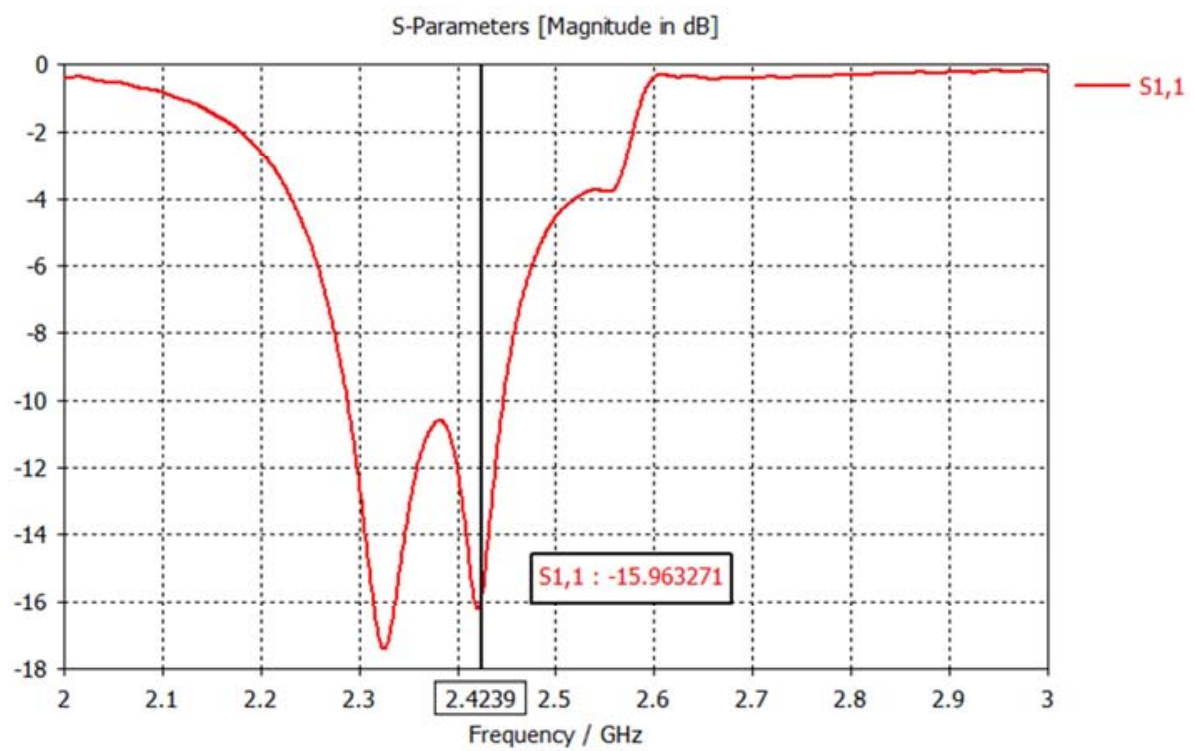

Figure 5. Return Loss at $2.4239 \mathrm{GHz}$.

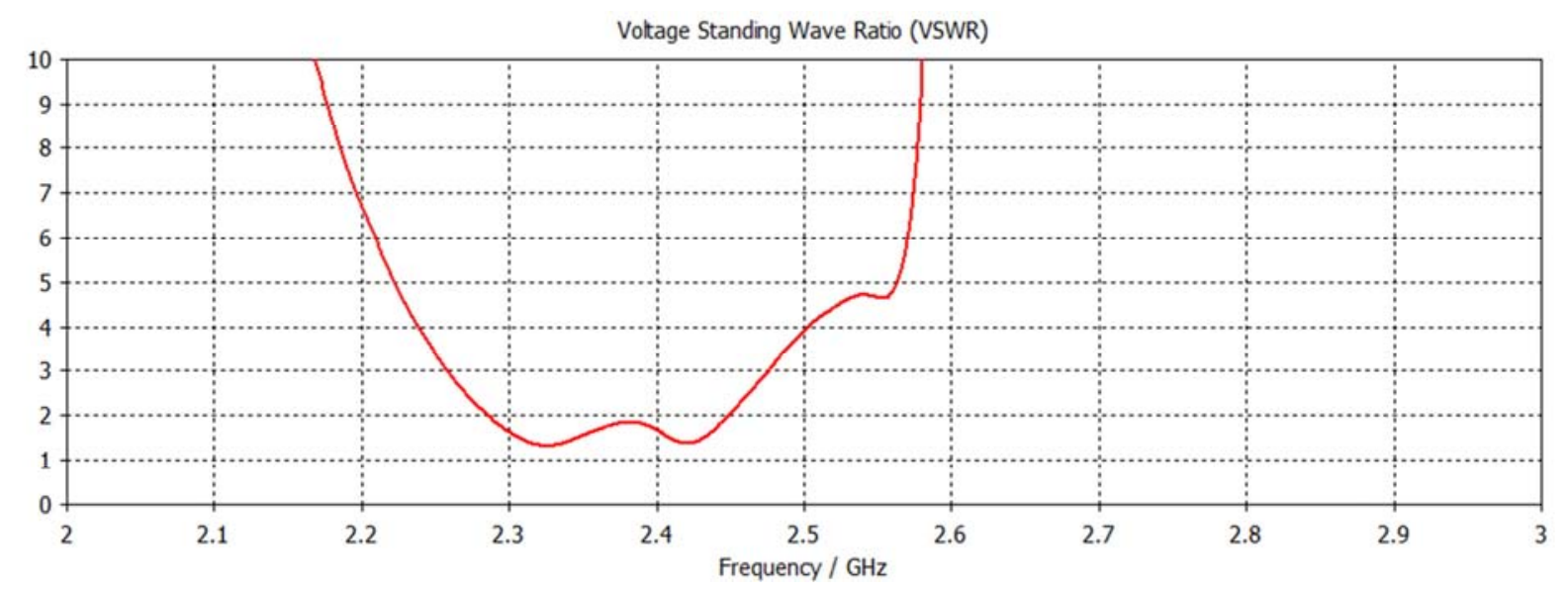

Figure 6. VSWR vs. Frequency.

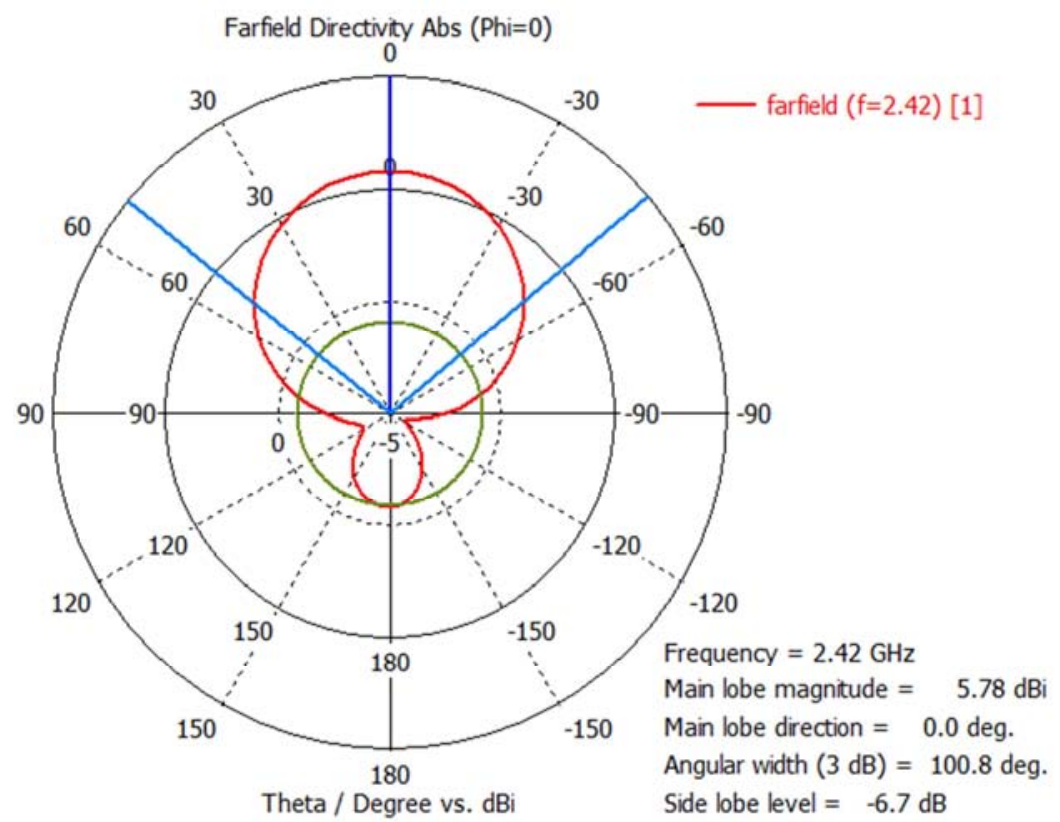

(a) E-plane 


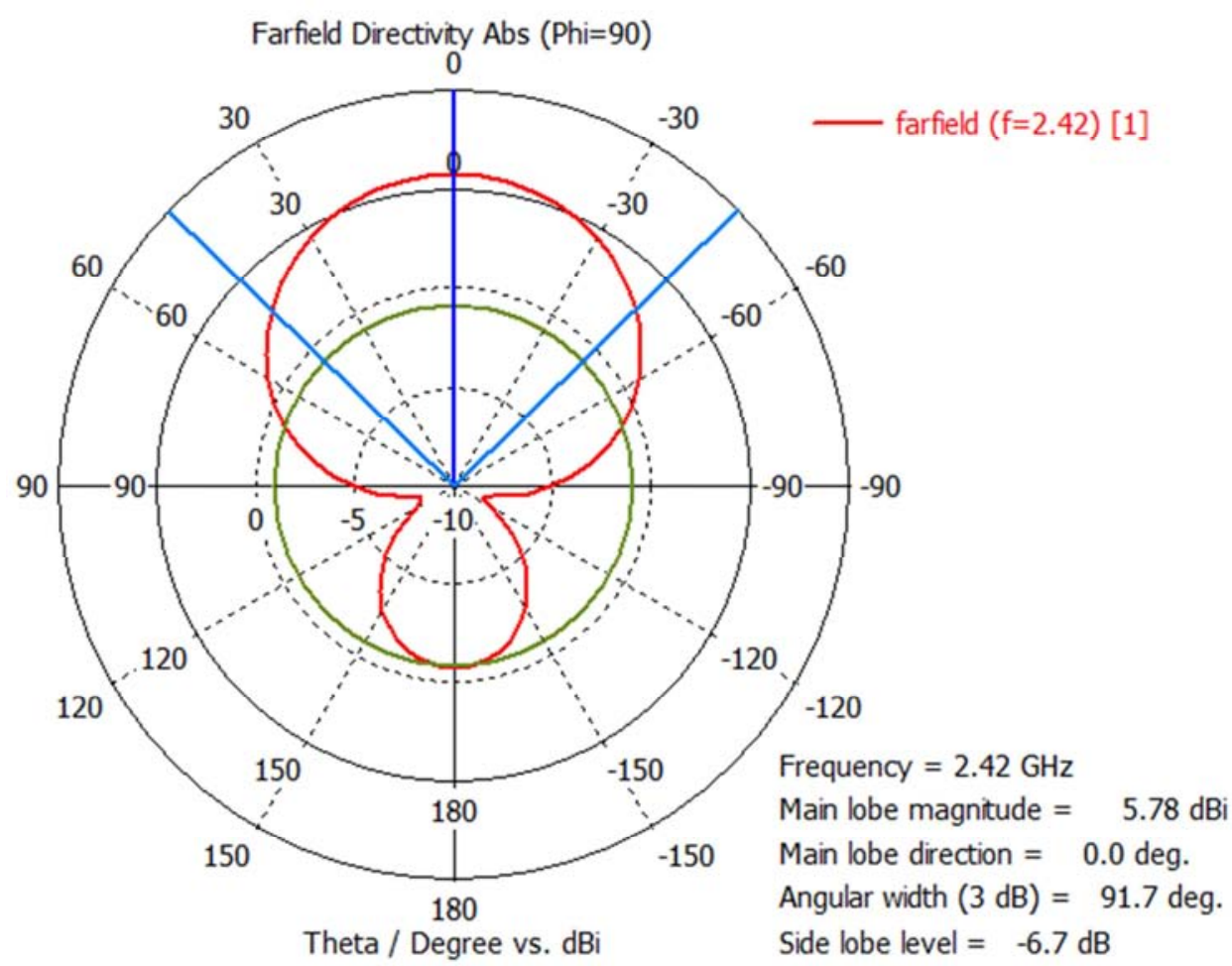

(b) H-plane

Figure 7. Radiation Pattern (a) Phi=0 deg, (b) Phi=90deg.

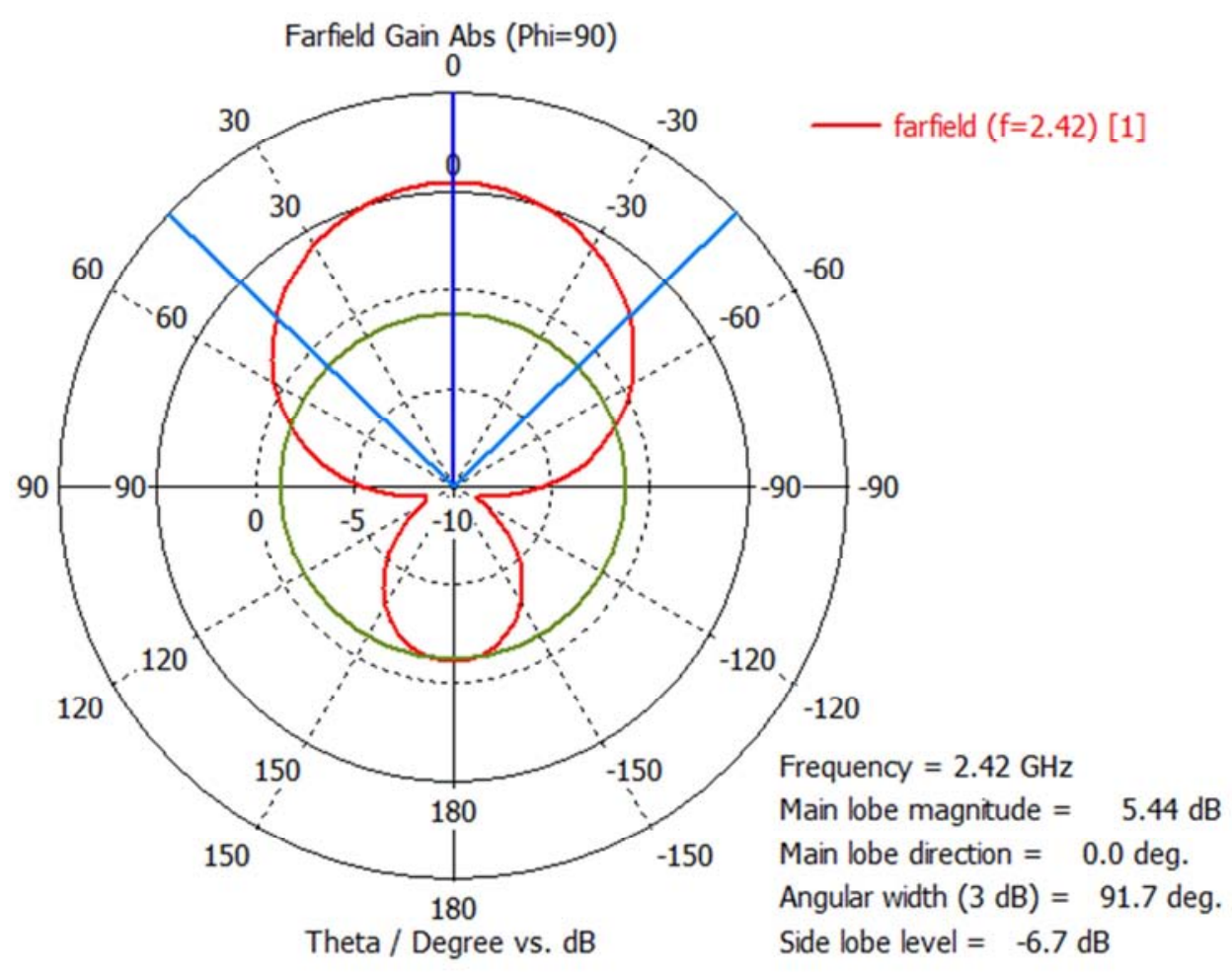

Figure 8. Gain at 2.4GH. 


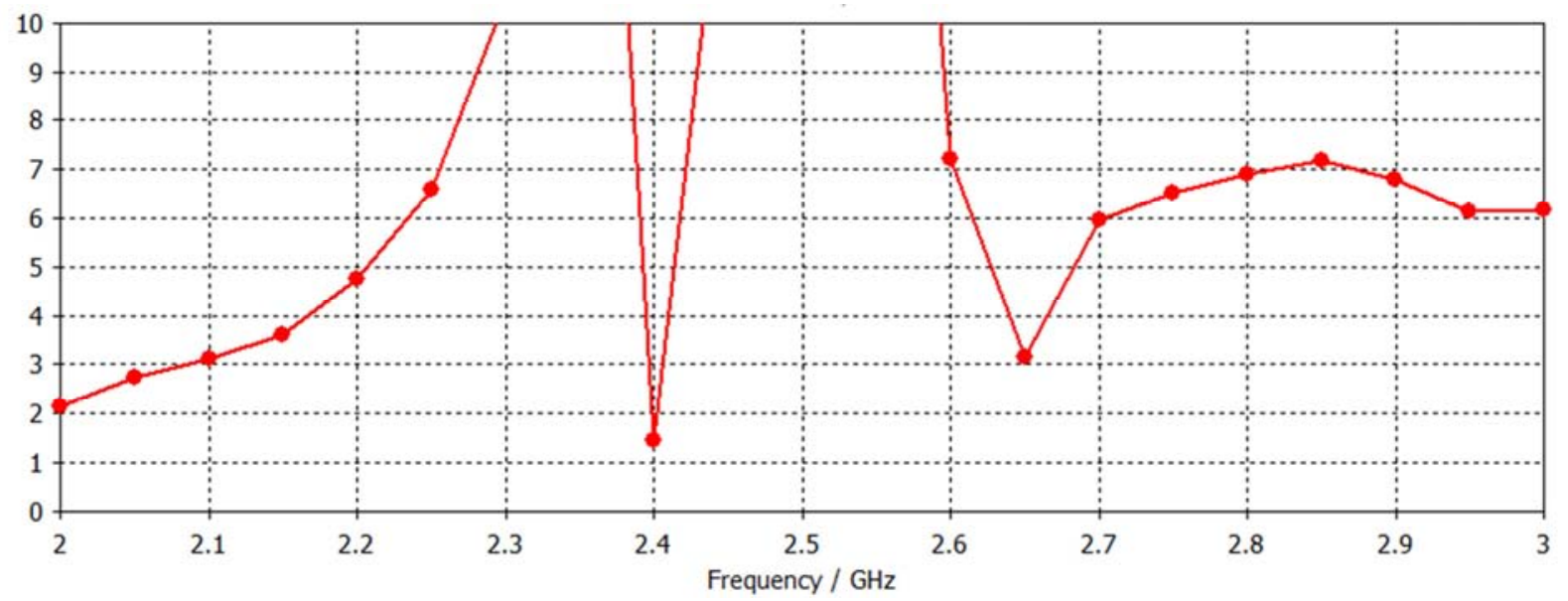

Figure 9. Axial ratio vs. Frequency.

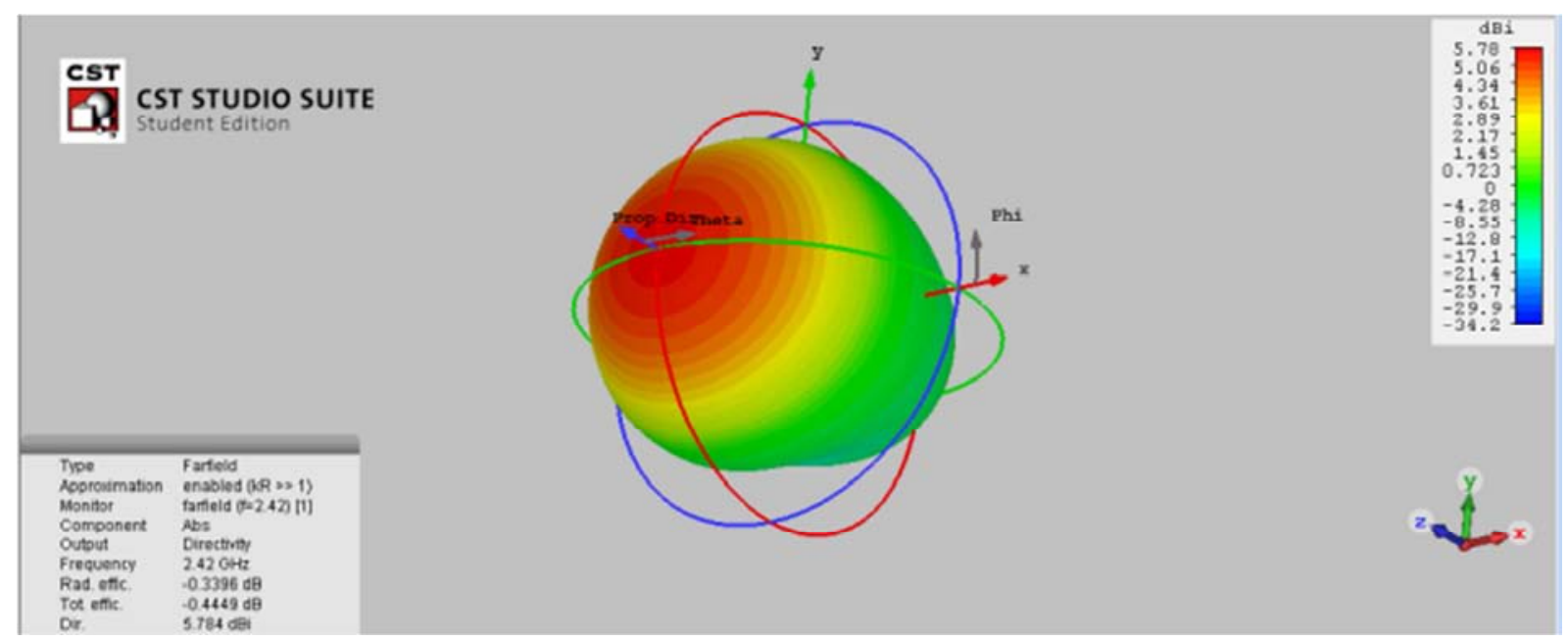

Figure 10. 3D far-field pattern at $2.42 \mathrm{GHz}$.

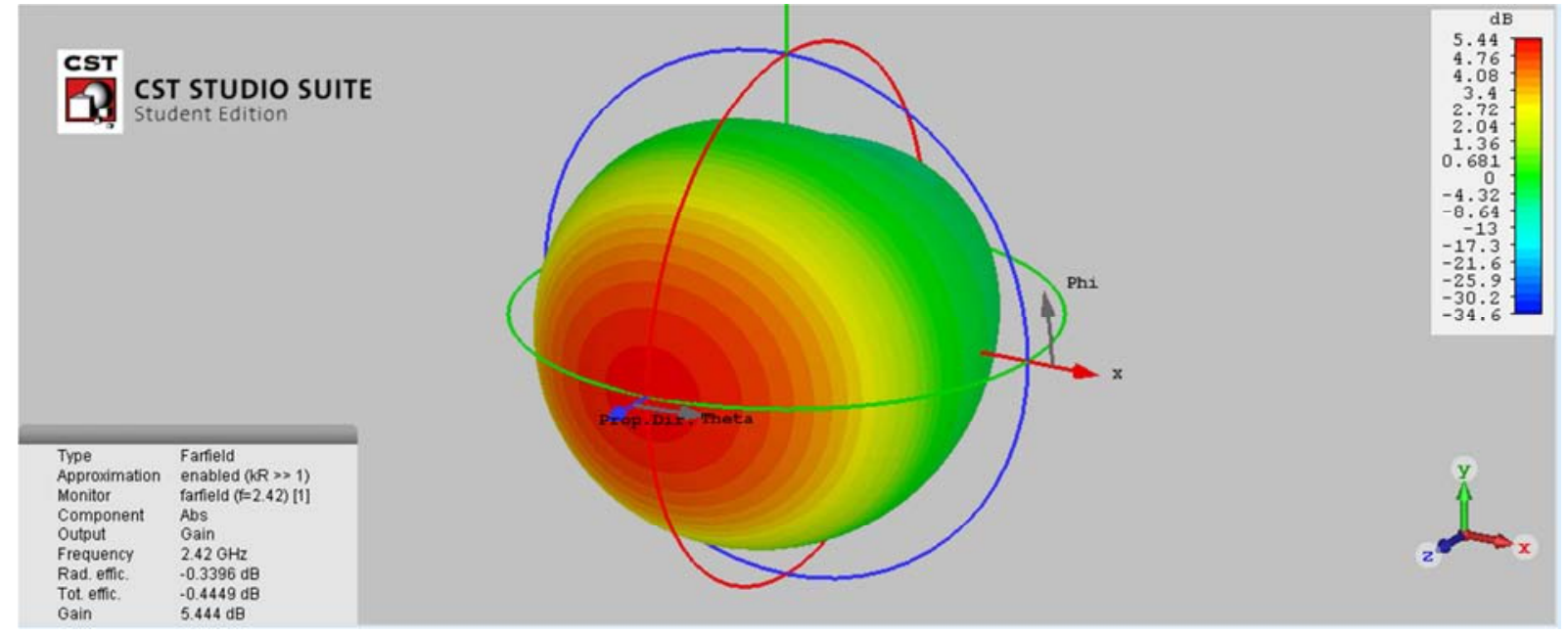

Figure 11. 3D gain pattern at $2.42 \mathrm{GHz}$.

\section{Conclusions}

The proposed frequency range at $2.42 \mathrm{GHz}$ and analysis Radiation Characteristics of microstrip patch antenna by CST STUDIO SUIT. The proposed antenna is designed on a FR-4 substrate with dielectric constant 4.4 . At $2.42 \mathrm{GHz}$ resonant frequency the verify and tested result on CST Microwave Studio are Return loss $=-16.207 \mathrm{~dB}$, VSWR $=1.5$, Directivity $=5.57 \mathrm{dBi}$, Gain $=5.85 \mathrm{~dB}$, Bandwidth $=$ $160.24 \mathrm{MHz}(6.67 \%)$ (at $|\mathrm{S} 1,1|<-10 \mathrm{~dB}$ and VSWR $<2$ ), Efficiency $=96.34 \%$ and Beamwidth at $3 \mathrm{~dB}=91.6^{\circ}$, all results shown in simulation results. Truncated corner in the 
patch cause circular polarization and return loss $(\mathrm{S} 1,1)$ is improved. Upper stack patch cause wide bandwidth is achieved. However, a good circular polarization at target resonant frequency is not achieved. The proposed antenna design is useful for wifi $(2.40-2.48 \mathrm{GHz})$ applications and CubeSat applications The future scope of work revolves around increasing the bandwidth up to $(9 \%)$ increased frequency range between $2300 \mathrm{MHz}-2500 \mathrm{MHz}$ and improving the axial ratio result closed to less than $3 \mathrm{~dB}$ in order to be a good circularly polarization by modifications in design of the proposed patch antenna. Detailed theoretical explanations can be derived to find out a best design with proper dimensions of proposed antenna.

Table 3. Simulation Results Of The Proposed Microstrip Patch Antenna.

\begin{tabular}{|c|c|c|c|}
\hline \multicolumn{4}{|l|}{ Simulation Results } \\
\hline Return loss & \multirow{8}{*}{ (n) } & -16.207 & $\mathrm{~dB}$ \\
\hline VSWR & & \multicolumn{2}{|l|}{1.5} \\
\hline Directivity (D) & & 5.75 & $\mathrm{dBi}$ \\
\hline Gain $(G)$ & & 5.54 & $\mathrm{~dB}$ \\
\hline Radiation Efficiency & & 96.34 & $\%$ \\
\hline \multirow[t]{3}{*}{ Bandwidth } & & 160.24 & $\mathrm{MHz}$ \\
\hline & & \multicolumn{2}{|c|}{$(2280 \mathrm{MHz}-2450 \mathrm{MHz})$} \\
\hline & & 6.67 & $\%$ \\
\hline Polarization & & $\mathrm{CP}$ & LHCP \\
\hline Axial Ratio & & $1.52 \mathrm{~dB}$ & At $2.42 \mathrm{GHz}$ \\
\hline
\end{tabular}

\section{Acknowledgements}

The authors would like to thank many colleagues from Antenna Engineering Research Group of Department of Electronic Engineering of Yangon Technological University.

\section{References}

[1] G. A. Deschamps, "Microstrip Microwave Antennas," Proc. $3^{\text {rd }}$ USAF Symposium on Antennas, 1953.

[2] R. E. Munson, "Single Slot Cavity Antennas Assembly," U. S Patent No. 3713162, January 23, 1973.

[3] R. E. Munson, "Conformal Microstrip Antennas and Microstrip Phased Arrays," IEEE Trans. Antenna Propagation, Vol. AP-22, pp. 74-78, 1974.

[4] J. Q. Howell, "Microstrip Antennas," IEEE Trans. Antenna Propagation, Vol. AP-23, pp. 90-93, January 1975.

[5] D. M. Pozar, "Microstrip Antennas," Proceedings of IEEE, Vol. 80, No. 1, January 1992.

[6] CST Microwave Studio by CST STUDIO SUIT STUDENT Version 2017.

[7] Microstrip Patch Antenna Design for KU Band Application, IFERT, ISSN:2278-0181, vol. 3 Issue 4, April, 2014.

[8] Stacked H-Shaped Microstrip Patch Antenna, IEEE Transactions On Antennas And Propagation, vol. 52, No. 4, April 2004.

[9] Warren L Stutzman_ Gary A Thiele-Antenna theory and design _ by Warren L. Stutzman and Gary A. Thiele.

[10] Antenna Theory, Analysis And Design, Third Edition by Constantine A. Balanis, Copyright 2005 by John Wiley \& Sons, Inc.

[11] Design of Cirular Polarized Dual Band Patch Antenna by Thomas Edling, ISSN: 1654-7616, UPTEC E11008. 